\title{
NON-FIRED BUILDING BLOCKS USING INDUSTRIAL WASTES
}

\author{
G. M. Sadiqul Islam*1, Sudipta Sarker'1, Monower Sadique² and Ali Abdulhussein Shubbar ${ }^{2}$ \\ ${ }^{I}$ Department of Civil Engineering, Chittagong University of Engineering \& Technology, Bangladesh \\ ${ }^{2}$ Department of Civil Engineering, Liverpool John Moores University, Liverpool L3 3AF, UK
}

Received: 20 December 2020

Accepted: 27 July 2021

\begin{abstract}
Bricks produced from traditional techniques and agricultural clay contribute considerably to the air pollutions in the world. Therefore, an urgent need to start using an environment-friendly alternative material/approach to save the fertile topsoil and conserve a clean environment. This research is aimed to produce non-fired bricks incorporating industrial solid waste from steel and power plants, including Fly ash and Ladle Furnace Slag (LFS), as a partial replacement of CEM I and lime. Induction Furnace Slag (IFS) is used as a partial/full replacement of natural fine aggregate (local sand) in the laboratory scale manufacturing process. The prepared building blocks conform to the minimum compressive strength requirement of 10.3 MPa per ASTM C62 and BDS 208 while the maximum compressive strength was $40.6 \mathrm{MPa}$. This highly promising performance pronounced the use of industrial waste materials in non-fired brick production to achieve a cleaner environment for a sustainable society.
\end{abstract}

Keywords: Ladle Furnace Slag (LFS), Induction Furnace Slag (IFS), Fly Ash, Industrial Waste management, Building block, Sustainability.

\section{INTRODUCTION}

People have been using bricks as an essential building construction material for thousands of years for their manifold superiorities over other earthen construction materials. Clay bricks dating back to 10,000 BCE, was found in Egypt, which was hand-moulded and sun-dried. The historic city Ur adopted clay bricks as the primary construction materials around $4000 \mathrm{BCE}$. Archaeological evidence has been found traced back $5000 \mathrm{BCE}$ on the use of fire to produce clay-based bricks for better performance. The brick industry has been on continuous development using modern machinery, such as powerful excavation equipment, motors, tunnel kilns. One thousand five hundred billion units fired brick production was estimated in 2015 globally (Climate and Clean Air Coalition, 2016). Despite the workability of conventional brick production, fired clay brick production consumes a considerable amount of virgin resources and energy. In the production of 1-tonne brick, an estimated $706 \mathrm{kWh}$ energy is required, and 0.15 -tonne carbon dioxide $\left(\mathrm{CO}_{2}\right)$ is being emitted (Carbon Trust, 2011). This considerable energy consumption and carbon footprint is a barrier to achieve sustainable development.

Apart from that, the construction contributes to a loss of $1 \%$ of agricultural land annually in Bangladesh. Approximately $80 \%$ of this loss is due to unplanned rural housing also over $17 \%$ for brick kilns. Excavation per hectare of fertile topsoil could cause up to Tk. 3.1 million economic loss (Ahmed, Hassan and Islam, 2021). The brick industries in this country produce approximately 25 billion units every year by eliminating 100 million tons of topsoil, considerably affecting agricultural production and achieving sustainable development. About 50 million people might face food shortages by 2050 when the population of the country is expected to reach 245 million (Correspondent, 2018). An annual 80 million tonnes of $\mathrm{CO}_{2}$ emission is estimated for this country, of which $1 / 4$ is accounted for only 7,900 registered (constructed following proper design and environmental rules) conventional brick kilns. The unregistered traditional brick kilns are even higher than the reported numbers. These kilns also consume three million tonnes of wood and 5 million tonnes of coal annually (Hossain, 2017). In Dhaka, $58 \%$ of air pollution is accounted for conventional brick kilns.

A survey by the Department of Environment (DoE) of Bangladesh during 2013-18 found brick kilns were contributed highest air pollution in seven major cities of the country. Narayangonj has the most polluted air, followed by Dhaka. During the production (dry) season, November-April, the air quality of these metropolises becomes extremely unhealthy by emitting a lot of particles into the air. Another study with Norwegian Institute for Air Research (NILU), DoE conducted during 2013-16 in Dhaka, and Chattogram city found that $58 \%$ of the primary air pollutants (Particulate Matter 2.5) originate from the conventional brick kilns. Therefore, the country 
requires an immediate urgent need to use environment-friendly alternative bricks to conserve the environment and save its fertile topsoil. Furthermore, turning to alternatives like compressed or thermal blocks incorporating waste residues is crucial in ensuring food security and sustainable development.

Studies have been conducted to produce sustainable bricks to minimize the enormous carbon footprint from this conventional clay brick making industry, considering environmental and economic issues (Preethi and Venkatarama Reddy, 2020). An alternative to conventional bricks could be cement-based building blocks from Ordinary Portland Cement (OPC). However, cement clinker production is highly energy-intensive; $1 \mathrm{~kg}$ clinker requires $1.5 \mathrm{kWh}$ energy and releases about $1 \mathrm{~kg}$ of $\mathrm{CO}_{2}$ to the atmosphere (Islam et al., 2011). In addition, the aggregates are obtained from quarrying and thus have the same issues as a clay-based brick. Current global waste generation volumes are approximately 1.3 billion metric tons per year and are expected to increase to 2.2 billion metric tons by 2025 . To reduce environmental pollution, decrease the amount of generated wastes and preserve virgin materials, thereby contributing to sustainability; researchers have made remarkable efforts to develop different bricks from various types of waste materials.

In the near future, coal-burning power plants will be the primary source of power generation in Bangladesh. The current power generation of the Barapukuria coal power plant is $525 \mathrm{MW}$, and approximately 1,09,200 Metric tonnes of fly ash is being generated every year (Tamim, Dhar and Hossain, 2013). Few of the local cement companies use fly ash to produce blended cement. However, they use imported fly ash as the local fly ash cannot be transported cheaply, and the ash management is not good. The situation will worsen once three other under-construction coal-burning power plants come into the complete generation of $3840 \mathrm{MW}$. Considering a linear interpolation, the annual production of fly ash will rise to 865,000 MT per annum from 2024 onwards. For a densely populated country like Bangladesh, this volume of fly ash is an enormous amount to dispose of. Considering the chemical composition of Fly ash, incorporating it in non-fired eco-friendly brick can be a twoway solution for this problem (Petrillo et al., 2016).

Bangladesh has over 400 steel mills of different categories and sizes with over 4 million tons annual production. Most of the Bangladesh steel industries use induction furnaces that produce approximately 3.2 million tons of steel every year and 250 thousand tons of Induction Furnace Slag (IFS) (Rahman et al., 2017). About 60-80 kg of Ladle Furnace Slag (LFS) is recovered to refine each ton of steel (Papayianni and Anastasiou, 2012). Some of this amount reintroduce in the production process. However, a considerable amount of LFS is dumped as a landfill. In addition, the chemical composition of the powder-like material indicates its potential as a supplementary cementitious material.

The supply chain, e.g., waste-to-resources, has been thoughtfully considered in many industrial parks around the globe (Rashad, 2019). However, conventionally dumping or landfilling the steel waste as management practice would negatively impact the surrounding environment, including further pollution. This practice also requires the excess cost to dispose of. The incorporation of steel mills waste materials in brick production could be a potential solution for managing these hazardous residues. Thus, strategic industries can take advantage of market opportunities and neutralize threats arising from environmental issues. This research aims to explore different options to produce non-fired brick/building blocks from several industrial solid wastes, including fly ash, LFS by complete or partial replacement of cementitious media such as Portland-based cement and lime powder. In addition, IFS is used to replace sand in the medium.

\section{MATERIALS AND METHODS}

\subsection{Materials}

Characterization of the raw materials is described, and then the performance of the material composition in the pressurized building block preparation system was evaluated in terms of compressive strength. Industrial wastes- LFS and fly ash is used as a supplementary binder in the production of the building block. Another steel industry waste material, IFS is used as filler/fine aggregate. CEM I, building lime, and local sands are other associated materials used in this research.

CEM I of strength class $52.5 \mathrm{~N}$ with fineness $99.3 \%$ (\#200 sieve) and building lime (passing through $1 \mathrm{~mm}$ sieve) obtained from local sources. Fly ash is obtained from the Barapukuria coal-burning power plant in Bangladesh, while the LFS and IFS are collected from BSRM Steel Mills Ltd., Bangladesh. The building block is prepared using a maximum of $73 \%$ fly ash (of total binder content). The LFS passing through a $2 \mathrm{~mm}$ sieve is used as a binder. Induction furnace slag (IFS) of two different sizes (0-4 mm; FM 2.33 and 4-8 mm; FM 3.54) is collected from BSRM steel mills Ltd. It is used as a full or partial replacement of sand. A maximum of $60 \%$ IFS (both same size proportion) of the total dry mix is used in the building block preparation. The local sand used for the study was prepared according to graded sand requirements ASTM C778-17. 


\subsection{Particle size distribution (PSD)}

The particle size distribution of binders (CEM I, fly ash, LFS, and building lime) is obtained using a LASER particle size analyser. Approximately $1 \mathrm{~g}$ of sample (fly ash/LFS) is dispersed in water using an ultrasonic attachment in the sample vessel of the equipment. For CEM I and lime, the material is dispersed in propanol (to prevent reaction). Commercial software is used to create particle size distributions from the degree of scattering of a collimated, monochromatic, dual laser beam (red and blue) passing through the mixture of sample and solvent. At least three measurements are carried out for each sample. Although repeated distributions are similar for a given material, an average distribution result of these, created by the computer software, is reported. Figure 1 shows the combined PSD of CEM I, fly ash, LFS, lime, and IFS after 1-hour grinding. The mean size of CEM I $(22.77 \mu \mathrm{m})$ and fly ash $(20.1 \mu \mathrm{m})$ was found similar. However, the other two binders, building lime $(49.37 \mu \mathrm{m})$ and LFS $(59.2 \mu \mathrm{m})$, gave a much larger mean particle size.

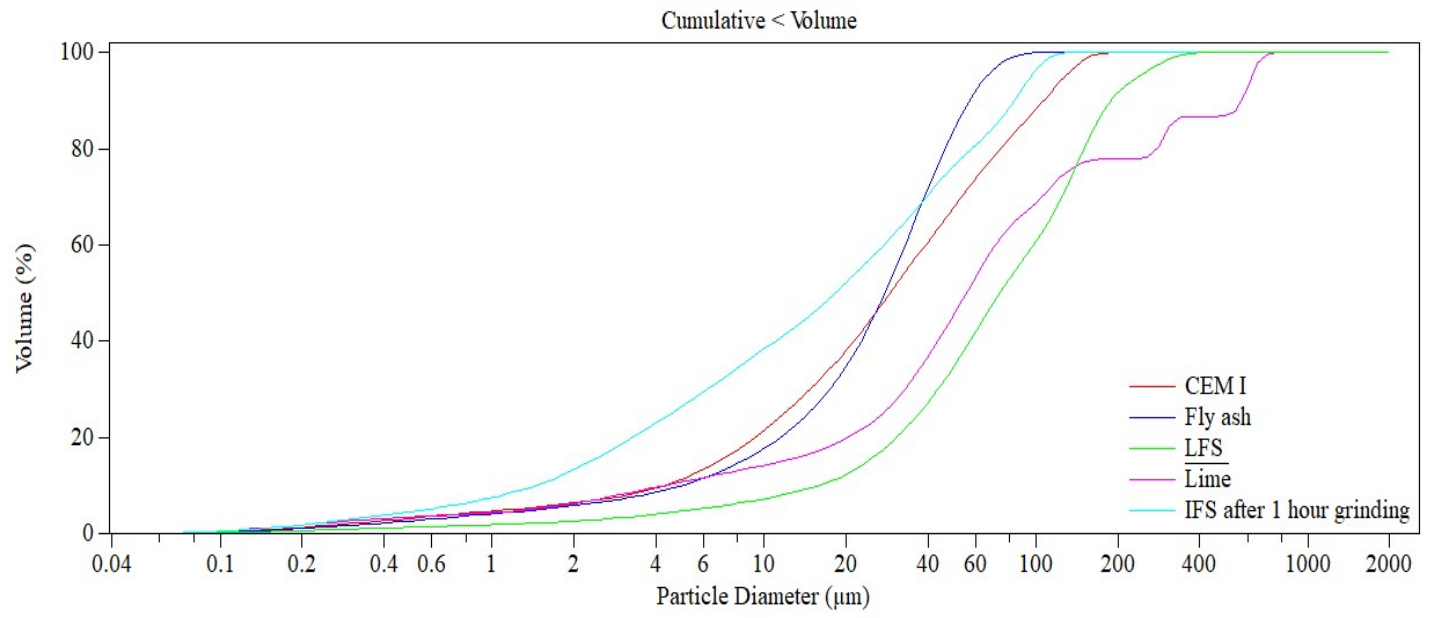

Figure 1: Particle Size Distribution of CEM I, Fly ash, LFS, Lime and IFS

\subsection{Chemical compositions of materials}

The chemical compositions of fly ash, steel slags (IFS and LFS) and other binders are determined using X-ray Florescence (XRF) technique. All these works are conducted at the Department of Pharmacy, Liverpool John Moore University, England. The chemical composition of fly ash satisfies the criteria of being low calcium fly ash (Class F) according to ASTM C618. In addition, the chemical composition of LFS shown in Table 1 conforms to that found in literature elsewhere.

Table 1: Chemical composition of materials used in this study

\begin{tabular}{llllllllll}
\hline Materials & $\mathrm{CaO} \%$ & $\mathrm{SiO}_{2} \%$ & $\mathrm{Al}_{2} \mathrm{O}_{3} \%$ & $\mathrm{Fe}_{2} \mathrm{O}_{3} \%$ & $\mathrm{MgO} \%$ & $\mathrm{Na}_{2} \mathrm{O} \%$ & $\mathrm{~K}_{2} \mathrm{O} \%$ & $\mathrm{TiO}_{2} \%$ & $\mathrm{MnO}^{2}$ \\
\hline IFS & 4.92 & 46.80 & 6.58 & 16.35 & 3.22 & 1.50 & 0.33 & 1.05 & 7.52 \\
FA & 0.71 & 52.92 & 17.12 & 2.58 & 0.43 & 0.32 & 0.77 & 2.78 & 0.01 \\
Lime & 93.26 & 1.085 & 0.56 & 0.66 & 0.75 & 1.93 & 0.09 & 0.11 & 1.01 \\
LFS & 47.44 & 29.35 & 5.57 & 0.74 & 2.27 & 1.57 & 0.09 & 0.89 & 1.61 \\
Cement & 64.38 & 22.36 & 4.59 & 2.81 & 2.08 & 1.52 & 0.72 & 0.63 & 0.04 \\
\hline
\end{tabular}

\subsection{Morphology analysis by SEM}

Figure 2 shows high magnification ESEM micrographs of the materials used in this study. SEM mode with an accelerating voltage of $15 \mathrm{kV}$ combined with a Links System Si(Li) X-ray detector is used. Selected samples are also analysed using the Energy-dispersive X-ray spectroscopy (EDX) mode at $20 \mathrm{kV}$ voltage to identify the nature of crystalline deposits on their surfaces. Double-sided adhesive carbon tape is secured to a $10 \mathrm{~mm}$ diameter aluminium stub, and the sample is sprinkled on it. Specimens are coated by Pd-Au alloy vapour to prevent charging during the test. 
The SEM image of CEM I is shown with a scale bar. Rest images were capture with the same magnification. As shown in Fig. 2, building lime particles are much smaller than CEM I. The fly ash was spherical with a cleaner surface, while LFS has an irregular shape with whitish deposits on its surface. The IFS is showing broken surfaces as it is obtained through ball milling.
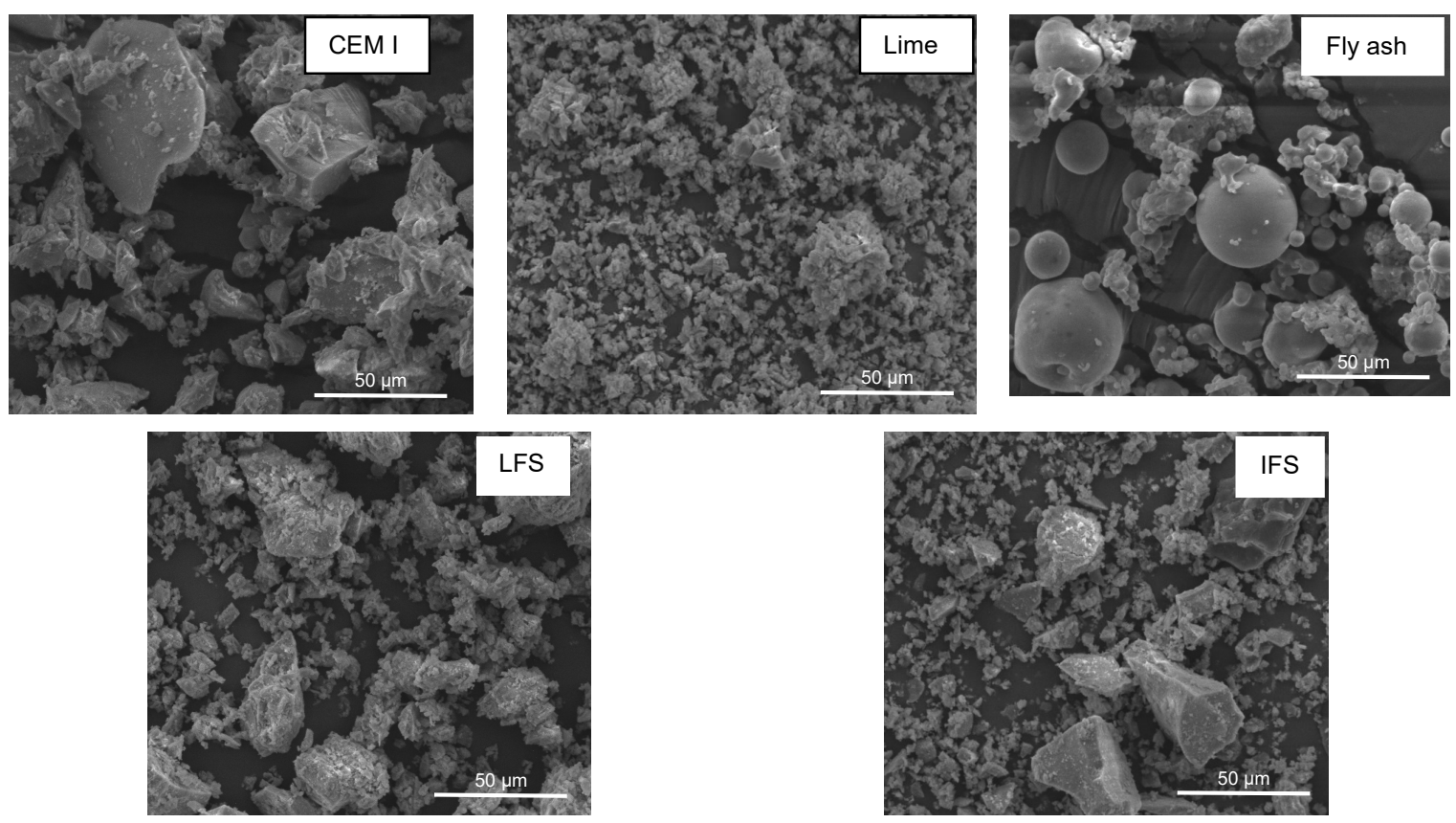

Figure 2: SEM images of materials used

\subsection{Mix Details and Preparation of Building Blocks}

Mix details of the fly ash-based and high-pressure building block are given in Tables 2 and 3, respectively. The required materials for building block preparation are first taken in an automatic pan mixer of $50 \mathrm{~kg}$ capacity. The mixer is kept rotating at a constant speed by a $1.5 \mathrm{~kW}$ motor. All the materials except water were mixed for 30 minutes. After adding water, the mixing process is continued for another 30 minutes. The quantity of water is added so that no water comes out after squeezing by hand from the mix, but moisture can be palpable in hand after finishing the mix. While the mixing continues, a further small quantity of water is also added if required (record also taken). As pressure is applied to compact the building blocks lowest possible amount of water (maximum amount of water used is $15.7 \%$ of total dry mix) is added in the mixing stage. An excess amount of water could bleed out while applying pressure.

Table 2: Mix details of fly ash building blocks $\left(\mathrm{kg} / \mathrm{m}^{3}\right)$

\begin{tabular}{ccccccc}
\hline \multirow{2}{*}{ Batch ID } & Water & \multicolumn{3}{c}{ Binder } & \multicolumn{3}{c}{ Fine Aggregate } \\
\cline { 3 - 7 } & & Fly ash & Cement & Lime & Local sand & IFS \\
\hline IF100C7.5LP7.5 & 248.0 & 651.0 & 122.1 & 122.1 & --- & 732.4 \\
IF67C7.5LP7.5 & 254.7 & 648.3 & 121.6 & 121.6 & 240.7 & 488.7 \\
IF33C7.5LP7.5 & 254.7 & 648.3 & 121.6 & 121.6 & 488.7 & 240.7 \\
IF00C7.5LP7.5 & 248.0 & 651.0 & 122.1 & 122.1 & 732.4 & --- \\
IF100C5LP10 & 234.4 & 656.4 & 82.1 & 164.1 & --- & 738.5 \\
IF100C10LP5 & 234.4 & 656.4 & 164.1 & 82.1 & --- & 738.5 \\
\hline
\end{tabular}

(IF100C7.5LP7.5 contains 100\% IFS as fine aggregate; $7.5 \%$ cement and lime each and $40 \%$ fly ash as a binder of the total dry mix by weight) 
Table 3: Mix details of high-pressure building blocks $\left(\mathrm{kg} / \mathrm{m}^{3}\right)$

\begin{tabular}{lccccc}
\hline \multirow{2}{*}{ Batch ID } & \multirow{2}{*}{ Water used } & \multicolumn{2}{c}{ Binder } & \multicolumn{2}{c}{ Fine Aggregate } \\
\cline { 3 - 6 } & & LFS & Cement & Local sand & IFS \\
\hline C10L05S25 & 159.6 & 111.4 & 222.7 & 556.9 & 1336.4 \\
C10L10S20 & 163.1 & 222.4 & 222.4 & 444.8 & 1334.4 \\
C10L15S15 & 163.1 & 333.6 & 222.4 & 333.6 & 1334.4 \\
C7.5L7.5S25 & 149.2 & 167.8 & 167.8 & 559.5 & 1342.7 \\
\hline
\end{tabular}

(C10L05S25: 10\%, 5\%, and 25\% of the total dry mix are CEM I, lime, and local sand, respectively. $60 \%$ of total dry mix was IFS. All quantity as weight basis)

\subsection{Casting and curing of the building block}

A mould of surface dimension $9^{\prime \prime} \times 4^{\prime \prime}(230 \mathrm{~mm} \times 102 \mathrm{~mm})$ is used for building block casting. The finished height is around $75 \mathrm{~mm}$. About $3.3 \mathrm{~kg}$ of freshly mixed materials is required for each fly ash building block preparation. For a high-pressure building block, approximately $4.2 \mathrm{~kg}$ mix was required. Fly ash blocks are greyish while high-pressure block without fly ash is brownish. Figures 3 and 4 give the compaction machine with its application for building block preparation.

Constant bar pressure is applied by hydraulic jack three times, summing a total of 11 seconds $(5 \mathrm{~s}+3 \mathrm{~s}+3 \mathrm{~s})$. In total, 70 and 200 bar pressure are used for fly ash and high-pressure building blocks. After casting, the blocks are taken from the mold instantly and kept at ambient temperature for 12 hours. Then those are kept underwater for seven days. On day eight, the samples are taken out of the water and kept at room temperature for the next 14 days. However, during this period, the blocks are immersed in water for 1 minute, at an interval of 8 hours. Then simple air curing was continued for the last seven days before testing at 28 days. Figure 5 shows the curing process of the building block samples. The pattern of curing was developed and followed to optimize curing cost considering strength gain patter earlier.
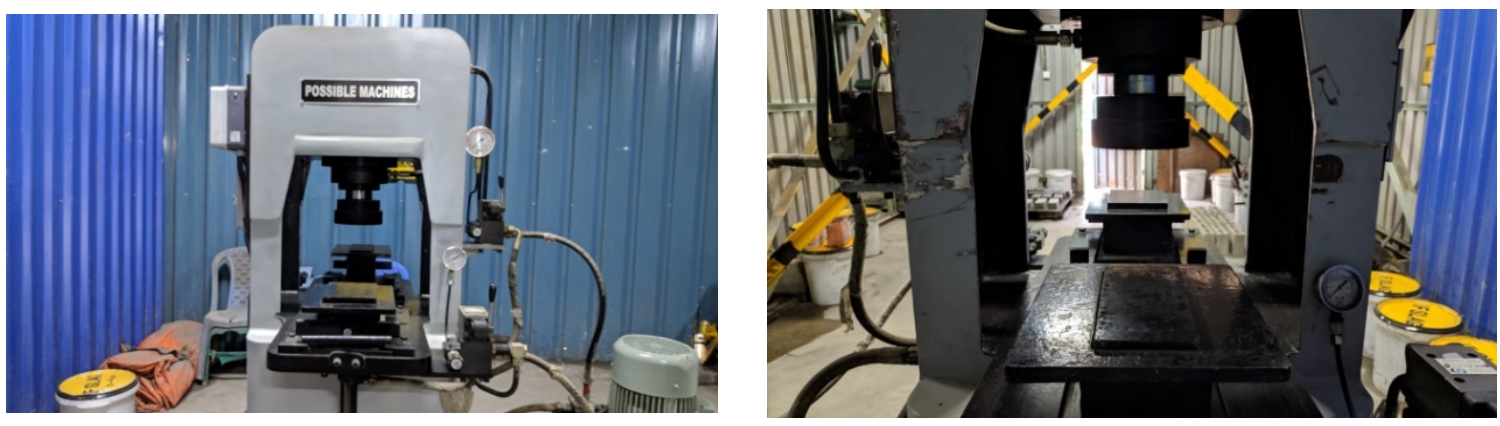

Figure 3: Building block casting machine
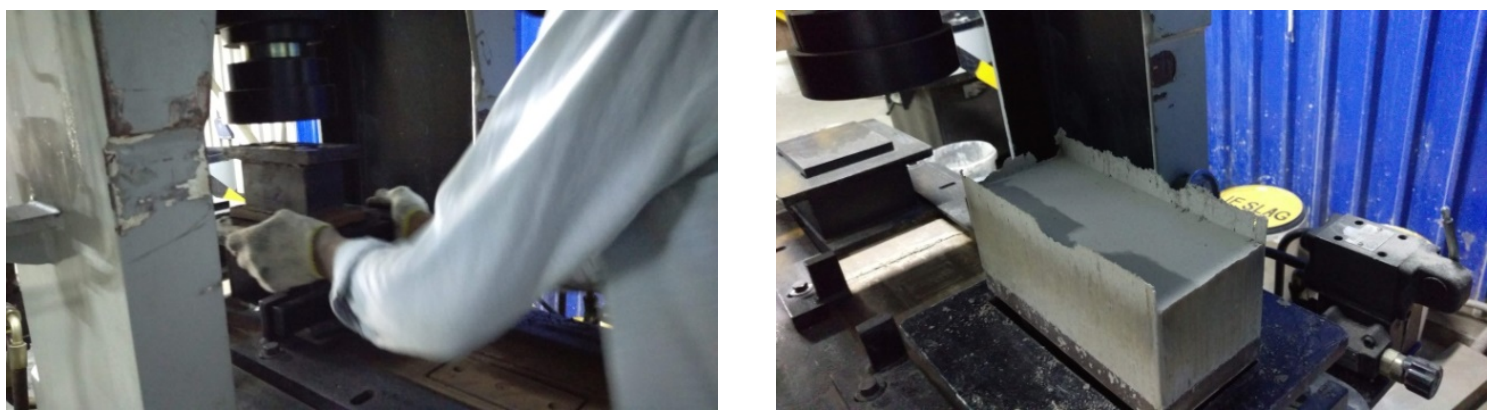

Figure 4: Pressure applying and casting 


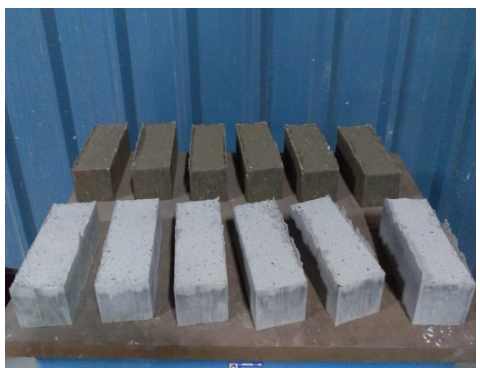

(a) Building blocks kept at ambient temperature

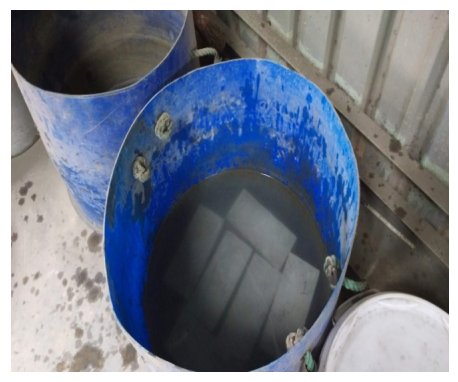

(b)Water curing of Building blocks

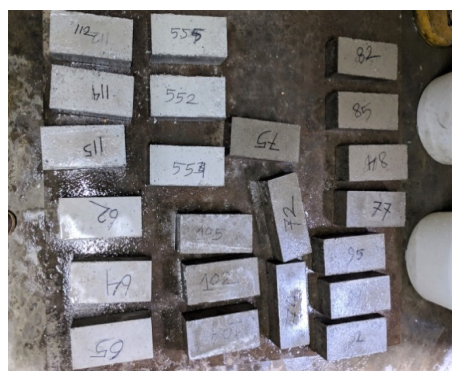

(c) Blocks after immersion in water for 1 minute

Figure 5: Curing process of building blocks

\subsection{Water Absorption and Compressive Strength Test}

The water absorption is calculated as the difference in weight after seven days of water curing and its weight before water curing and expressed in percentage. The compressive strength of a material is the uniaxial compressive stress reached when the material fails. For building blocks, three blocks were tested in each case, and the average value of these three was reported as per ASTM C39-18.

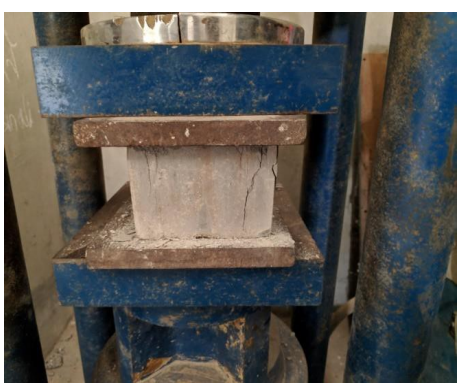

(a) Compression test set up

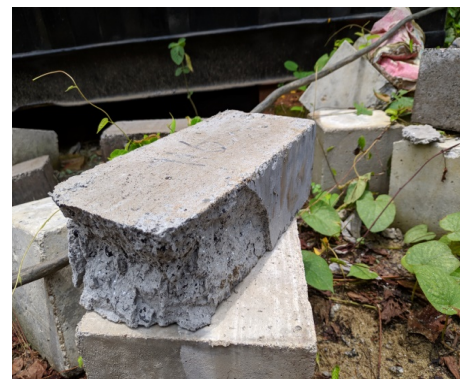

(b) Fly ash block

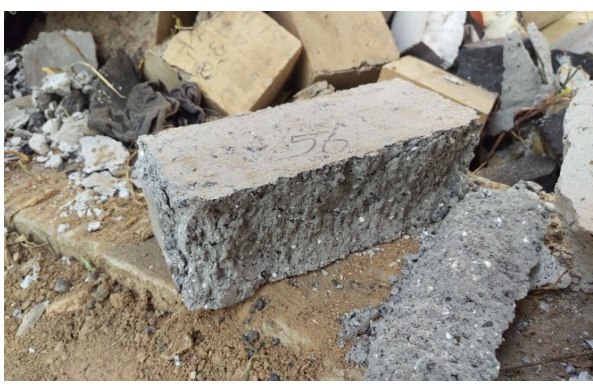

(c) High-pressure block

Figure 6: Compressive strength test and failure planes of building blocks

\section{RESULTS AND DISCUSSIONS}

\subsection{Fly Ash Based Building Blocks}

Fly ash incorporated building blocks are prepared using a ternary combination of CEM I, fly ash, and lime as a binder with IFS and local sand as fine aggregate. Table 4 gives details of binder and fine aggregate combination and their corresponding compressive strength. Among these combinations mentioned, IF00C7.5LP7.5 gives the maximum compressive strength of $18.5 \mathrm{MPa}$ and $40.6 \mathrm{MPa}$ at 7 and 28 days. The sample incorporated $100 \%$ IFS (45\% of total mix content) as fine aggregate, while the rest, $55 \%$ of the mix, includes $40 \%$ fly ash and $7.5 \%$ CEM I and lime each. With a gradual increase in CEM I content, 28 days compressive strengths are increased. For a fixed content of binder (fly ash, lime, and cement) highest strength is obtained with local sand as fine aggregate.

Table 4: Compressive strength of fly ash-based blocks

\begin{tabular}{|c|c|c|c|c|c|c|c|c|}
\hline \multirow{3}{*}{ SAMPLE } & \multicolumn{6}{|c|}{ Materials, $\%$ of total dry mix } & \multirow{2}{*}{\multicolumn{2}{|c|}{ Compressive Strength (MPa) }} \\
\hline & \multicolumn{3}{|c|}{ Binder } & \multicolumn{2}{|c|}{ Fine Aggregate } & \multirow{2}{*}{ water } & & \\
\hline & Cement & Fly Ash & Lime & IFS & Fine sand & & 7 Days & 28 Days \\
\hline IF100C7.5LP7.5 & 7.5 & 40 & 7.5 & 45 & --- & 15.2 & 11.8 & 19.1 \\
\hline IF67C7.5LP7.5 & 7.5 & 40 & 7.5 & 30 & 15 & 15.7 & 11.3 & 23.7 \\
\hline IF33C7.5LP7.5 & 7.5 & 40 & 7.5 & 15 & 30 & 15.7 & 14.1 & 26.6 \\
\hline IF00C7.5LP7.5 & 7.5 & 40 & 7.5 & --- & 45 & 15.2 & 18.5 & 40.6 \\
\hline IF100C5LP10 & 5.0 & 40 & 10.0 & 100 & 0 & 14.3 & 9.2 & 14.4 \\
\hline IF100C10LP5 & 10.0 & 40 & 5.0 & 100 & 0 & 14.3 & 9.6 & 20.3 \\
\hline
\end{tabular}




\subsection{Effect of IFS and Lime in Fly ash Blocks}

Figure 7 shows the variation of strength for $0 \%, 33 \%, 67 \%$ and $100 \%$ replacement of local sand by IFS. Approximately $40-50 \%$ strength is increased at 28 days from that obtained at seven days. With the gradual increase in IFS content, compressive strength decreased. At 28 days, the decrease of strength (14 MPa) is high between 0 to $33 \%$ replacements of sand by IFS. After that, the strength decreases at a slower rate, and $100 \%$ IFS (as aggregate) gives $47 \%$ strength of blocks with $100 \%$ sand (as aggregate). At seven days, the strength variation is relatively more minor. The lowest strength is obtained for building blocks with $67 \%$ IFS $+33 \%$ local sand aggregate. Building blocks used 100\% IFS gives $11.8 \mathrm{MPa}$, which still satisfies the minimum strength requirement by ASTM C62-17 (standard specification for building bricks). Therefore, even if the compressive strength is lower than the local sand, $100 \%$ IFS could be used as fine aggregate to produce building blocks to apply in non-exposed weather conditions such as interior partition walls as per ASTM C62 (ASTM, 2017) requirements.

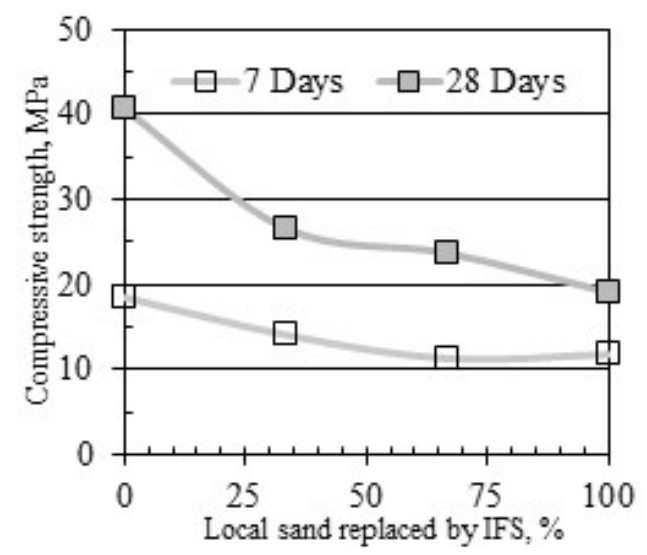

Figure 7: Compressive strength vs sand replaced by IFS (40\% fly ash)

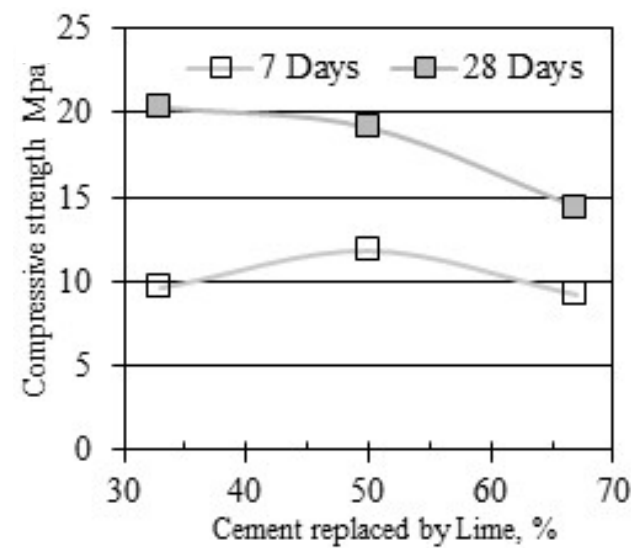

Figure 8: Compressive strength vs \% cement replaced by lime ( $40 \%$ fly ash)

Considering 28 days compressive strength, it is evident from Figure 8 that with the increase in CEM I replacement by lime, compressive strength decreased. The 28-day compressive strength reduces to $14.4 \mathrm{MPa}$ from $20.3 \mathrm{MPa}$, while cement replacement increases from $33 \%$ to $67 \%$. However, the reduction for $50 \%$ cement replacement is minor, and therefore, it could be concluded that the lime and fly ash combination could work similar to that of cement and fly ash.

\subsection{High-pressure Building Blocks}

High pressure (200 bar) building blocks are prepared using 60\% IFS with a limited amount of local sand (15$25 \%)$, and instead of lime and fly ash, LFS was used on a limited scale (5-15\%). Table 5 shows mixed combination and their compressive strength at 7 and 28 days. Sample C10L10S20 gives the highest 7- and 28days strength than all other batches. 10\% LFS is found optimum considering the same amount of IFS (60\%) and Cement (10\%) are used. C10L05S25 shows the lowest 28 days strength of $29.4 \mathrm{MPa}$. Nonetheless, the average strength of high-pressure building blocks is higher than the average strength of fly ash incorporated blocks indicating a significant contribution of high pressure in obtaining compressive strength.

Table 5: Mix combination and compressive strength of high-pressure building block

\begin{tabular}{ccccccccc}
\hline SAMPLE & \multicolumn{3}{c}{ Mix combination, \% dry mix } & $\begin{array}{c}\text { water } \\
\text { content, \% }\end{array}$ & $\begin{array}{c}\text { water } \\
\text { absorption \% }\end{array}$ & \multicolumn{2}{c}{$\begin{array}{c}\text { Compressive } \\
\text { Strength (MPa) }\end{array}$} \\
\cline { 2 - 9 } & IFS & Cement & LFS & Fine sand & & & 7 Days & 28 Days \\
\hline C10LRF05S25 & 60.0 & 10.0 & 5.0 & 25.0 & 7.2 & 2.6 & 25.2 & 29.4 \\
C10LRF10S20 & 60.0 & 10.0 & 10.0 & 20.0 & 7.3 & 3.2 & 27.2 & 38.0 \\
C10LRF15S15 & 60.0 & 10.0 & 15.0 & 15.0 & 7.3 & 3.2 & 25.6 & 34.1 \\
C7.5LRF7.5S25 & 60.0 & 7.5 & 7.5 & 25.0 & 6.7 & 3.0 & 23.1 & 31.1 \\
\hline
\end{tabular}




\subsection{Effect of LFS content on the high-pressure building block}

As shown in Figure 9, 10\% LFS content gives better compressive strength performance both in 7 and 28 days. On the other hand, 5\% LFS content gives the lowest compressive strength in 7 and 28 days. The strength increment rate for $10 \%$ LFS content is the highest among all the samples. For this, the 28 days compressive strength is $10.8 \mathrm{MPa}$ greater than that of 7 days compressive strength.

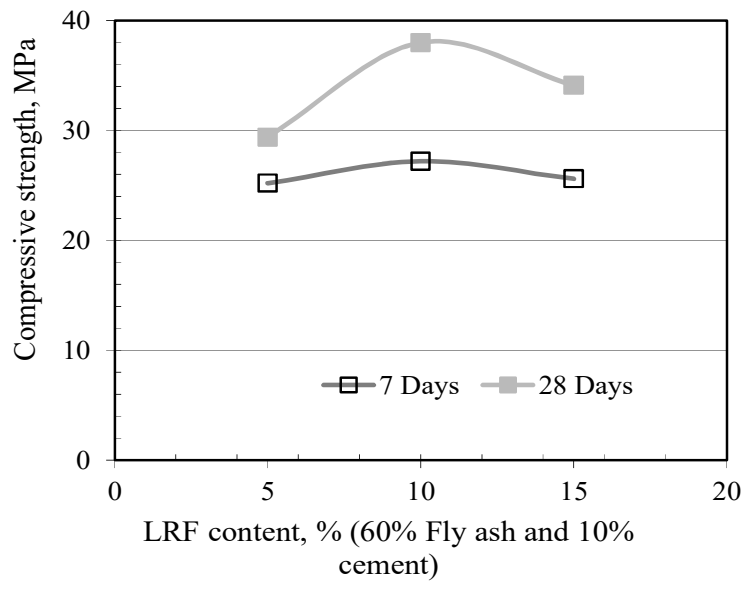

Figure 9: Compressive strength VS \% LFS content

\subsection{Excess water absorption and compressive strength of high-Pressure building block}

The original total weight of the ingredients required to produce one building block is noted. After seven days of underwater curing, the samples were surface dried and weighted. Figure 10 and 11 shows the water absorption rate (\%) and compressive strength of fly ash incorporated building blocks and high-pressure building blocks. For fly ash blocks, the highest 7-day compressive strength $(18.5 \mathrm{MPa})$ is obtained for the IF00C7.5L7.5 batch, giving lower water absorption (2.8\%). Generally, higher water absorption (above 3\%) is obtained for the samples having low compressive strength (below 10MPa).

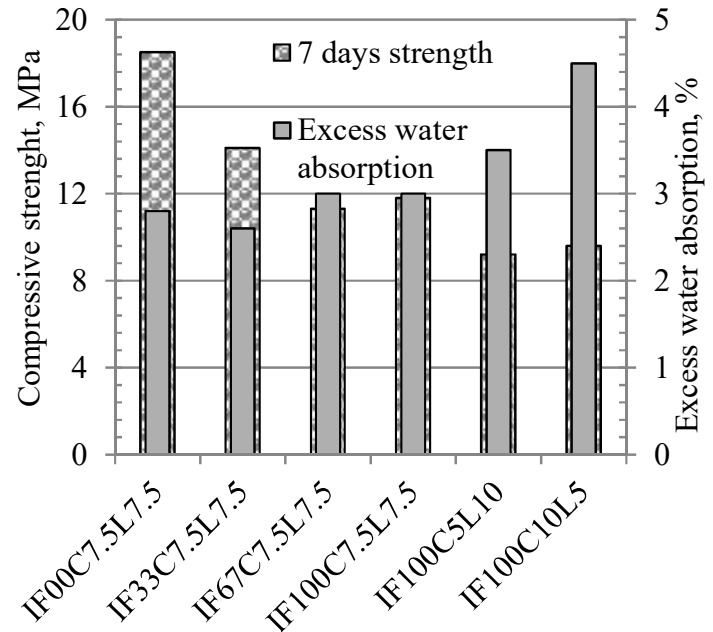

Figure 10: Water absorption (\%) and compressive strength of fly ash-based building block.

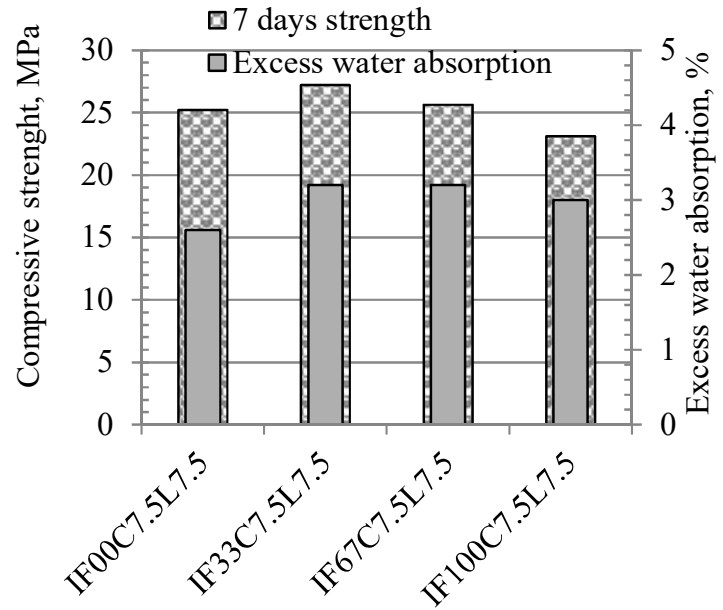

Figure 11: Water absorption (\%) and compressive strength of high-pressure building block.

The water absorption is negligible $(\leq 3 \%)$ for highly pressurized building blocks; however, no definite correlation was found between the seven days of excess water absorption and compressive strength. The highest compressive strength at seven days was found to be $27.2 \mathrm{MPa}$, for which excess water absorption is $3.2 \%$. C10L05S25 sample gives the lowest water absorption (2.6\%), for which the strength is $25.2 \mathrm{MPa}$. Though it is not the lowest seven days strength, its 28 days strength $(29.4 \mathrm{MPa})$ is the lowest. The water absorption rate for every sample of the high-pressure system always gives a lower value than that of a fly ash based building block. 
This is due to around 2000 psi higher pressure is applied to the high-pressure building block. In the mix, fly ash requires a higher level of water to make it workable

\section{CONCLUSIONS}

The research aimed to assess the feasibility of non-fired brick/building block production using waste materials. In this regard, the compressive strength of fly ash-based blocks ( 70 bar pressure) increases with the replacement of IFS by local sand, and maximum strength of 40.6 MPa was achieved. By applying a higher pressure (200 bar), the compaction level was improved, which increased the building blocks' compressive strength. Overall, the study with potential waste materials gave a promising indication that these materials could be used as an alternative to clay brick production with further modification. Researchers have considerable scope for further development to improve the quality of bricks. Durability tests such as chloride penetration/carbonation, water and gas permeability, dimensional performance/efflorescence, leaching of any heave metal/harmful constituents from the building blocks are required to carry out its efficient use. For pressurized building blocks, the effect of variable compaction pressures could be evaluated. Strength performance with other waste materials such as rice Husk Ash, ceramic waste could also be evaluated.

\section{ACKNOWLEDGEMENT}

The financial support to carry out the project was received from Research England. The laboratory support provided by Chittagong University of Engineering \& Technology (CUET), Bangladesh and Liverpool John Moors University, England are gratefully acknowledged. Material support was received from BSRM Steel Mills Ltd., Royal Cement Ltd. and Barapukuria Coal Power Plant. This is to declare that a part of this paper has been presented in ICCESD 2020 conference.

\section{REFERENCES}

Ahmed, E., Hassan, S. M. and Islam, G. M. S. (2021) 'Effect of compaction pressur on the properties of ecofriendly building block produced from industrial by-products', in 5th International Conference on Advances in Civil Engineering (ICACE-2021), 4-6 March 2021 CUET, Chattogram, Bangladesh.

ASTM (2017) 'ASTM C62, Standard specification for building brick (solid masonry units made from clay or shale)’, Annual Book of ASTM Standards. West Conshohocken, PA, USA. doi: 10.1520/C0062-17.

Carbon Trust (2011) 'Guide to the brick sector'.

Climate and Clean Air Coalition (2016) Mitigating black carbon and other pollutants from brick production. Available at: www.ccacoalition.org/en/initiatives/bricks (Accessed: 31 July 2020).

Correspondent, S. (2018) 'Shun burnt bricks to save topsoil', The Daily Star, p. Back page. Available at: www.thedailystar.net/backpage/news/manufacturing-burnt-bricks-100m-tonnes-top-soil-ruined-year1636384 (Accessed: 2 August 2020).

Hossain, M. (2017) To cut brick kiln pollution, Bangladesh constructs new building materials | Reuters. Available at: www.reuters.com/article/us-bangladesh-construction-climatechange-idUSKBN1D81IA (Accessed: 31 May 2021).

Islam, G. M. S. et al. (2011) 'Green Construction Materials - Bangladesh Perspective', in International Conference on Mechanical Engineering and Renewable Energy (ICMERE2011). Chittagong: Department of Mechanical Engineering, CUET, Bangladesh.

Papayianni, I. and Anastasiou, E. (2012) 'Effect of granulometry on cementitious properties of ladle furnace slag', Cement and Concrete Composites. Elsevier, 34(3), pp. 400-407. doi: 10.1016/j.cemconcomp.2011.11.015.

Petrillo, A. et al. (2016) 'Eco-sustainable Geopolymer Concrete Blocks Production Process', Agriculture and Agricultural Science Procedia. Elsevier BV, 8, pp. 408-418. doi: 10.1016/j.aaspro.2016.02.037.

Preethi, R. K. and Venkatarama Reddy, B. V. (2020) 'Experimental investigations on geopolymer stabilised compressed earth products', Construction and Building Materials. Elsevier Ltd, 257. doi: 10.1016/j.conbuildmat.2020.119563.

Rahman, M. S. et al. (2017) 'Investigation of Heavy Metals and Radionuclide's Impact on Environment Due to The Waste Products of Different Iron Processing Industries in Chittagong, Bangladesh', Journal of Environmental Protection. Scientific Research Publishing, Inc, 08(09), pp. 974-989. doi: 10.4236/jep.2017.89061. 
Rashad, A. M. (2019) 'A synopsis manual about recycling steel slag as a cementitious material', Journal of Materials Research and Technology. Elsevier. doi: 10.1016/J.JMRT.2019.06.038.

Tamim, M. M., Dhar, A. and Hossain, M. S. (2013) 'Fly ash in Bangladesh- an Overview', International Journal of Scientific \& Engineering Research, 4(4). doi: SSN 2229-5518.

(C) 2021 JES. Journal of Engineering Science published by Faculty of Civil Engineering, Khulna University of Engineering \& Technology. This is an open access article under the terms of the Creative Commons Attribution-NonCommercialNoDerivatives License, which permits use and distribution in any medium, provided the original work is properly cited, the use is non-commercial and no Modifications or adaptations are made. 